\title{
A needle in a haystack: Mesozoic origin of parasitism in Strepsiptera revealed by first definite Cretaceous primary larva (Insecta)
}

\author{
Hans Pohl ${ }^{\text {Corresp., }}{ }^{1}$, Jan Batelka ${ }^{2}$, Jakub Prokop ${ }^{2}$, Patrick Müller ${ }^{3}$, Margarita I Yavorskaya ${ }^{1}$, Rolf G Beutel ${ }^{1}$ \\ ${ }^{1}$ Institut für Zoologie und Evolutionsforschung, Spezielle Zoologie und Entomologie, Friedrich-Schiller Universität Jena, Jena, Germany \\ 2 Department of Zoology, Faculty of Science, Charles University Prague, Praha, Czech Republic \\ 3 Käshofen, Germany \\ Corresponding Author: Hans Pohl \\ Email address: hans.pohl@uni-jena.de
}

Twisted winged insects (Strepsiptera) are a highly specialized small order of parasitic insects. Whether parasitism developed at an early or late stage in the evolution of the group was unknown. Here we record and describe the first definite Mesozoic strepsipteran primary larva embedded in Burmese amber ( 99 million years ago). This extends the origin of the parasitism back by at least $\sim 50$ million years, and reveals that this specialized life style has evolved in the Mesozoic or even earlier in the group. The extremely small first instar displays all diagnostic characters of strepsipteran immatures of this stage and is nearly identical with those of Mengenillidae, one of the most "ancestral" extant strepsipteran taxa. This demonstrates a remarkable evolutionary stasis over 100 million years. The new finding strongly weakens the case of small larvae embedded in Cretaceous amber interpreted as strepsipteran immatures. They differ in many structural features from extant strepsipteran primary larvae and are very likely parasitic beetle larvae. 
1 A needle in a haystack: Mesozoic origin of parasitism in Strepsiptera revealed by first

2 definite Cretaceous primary larva (Insecta)

3 Hans Pohl ${ }^{1}$, Jan Batelka ${ }^{2}$, Jakub Prokop ${ }^{2}$, Patrick Müller ${ }^{3}$, Margarita I. Yavorskaya ${ }^{1}$, Rolf G.

4 Beutel $^{1}$

5

$6{ }^{1}$ Institut für Zoologie und Evolutionsforschung, Friedrich-Schiller-Universität Jena, Germany

$7 \quad 2$ Department of Zoology, Faculty of Science, Charles University, Praha, Czech Republic

$8{ }^{3}$ Käshofen, Germany

9

10 Corresponding author

11 Hans Pohl

12 Email address: hans.pohl@uni-jena.de

13 


\section{Abstract}

15 Twisted winged insects (Strepsiptera) are a highly specialized small order of parasitic insects. 16 Whether parasitism developed at an early or late stage in the evolution of the group was 17 unknown. Here we record and describe the first definite Mesozoic strepsipteran primary larva 18 embedded in Burmese amber ( $\sim 99$ million years ago). This extends the origin of the parasitism back by at least $\sim 50$ million years, and reveals that this specialized life style has evolved in the Mesozoic or even earlier in the group. The extremely small first instar displays all diagnostic characters of strepsipteran immatures of this stage and is nearly identical with those of Mengenillidae, one of the most "ancestral" extant strepsipteran taxa. This demonstrates a remarkable evolutionary stasis over $\sim 100$ million years. The new finding strongly weakens the case of small larvae embedded in Cretaceous amber interpreted as strepsipteran immatures. They differ in many structural features from extant strepsipteran primary larvae and are very likely parasitic beetle larvae.

\section{Introduction}

Strepsiptera is a highly specialized small order of holometabolous insects (Pohl \& Beutel, 2008; 2013). The phylogenetic placement of the group, one of the longest controversies in systematic entomology, was only recently clarified (Niehuis et al., 2012; Peters et al., 2014; Misof et al., 2014; Kjer et al., 2016). The oldest recorded fossils are known from Cretaceous Burmese amber (Grimaldi, Kathirithamby \& Schawaroch, 2005; Pohl \& Beutel, 2016; Engel et al., 2016), indicating a minimum age of ca. 100 mya. An age of origin of ca. 120 mya was estimated based on molecular data (McMahon, Hayward \& Kathirithamby, 2011). However, the confirmed sister group relationship with Coleoptera (Misof et al., 2014) implies that the group originated already in the early Permian or late Carboniferous (McKenna et al., 2015; Toussaint et al., 2017).

Extant strepsipterans are characterized by a conspicuous sexual dimorphism. The winged males are free living but extremely short-lived. With well-developed sensory organs and a highly efficient flight apparatus they are able to find the females within their very short life span of only few hours. Females are wingless and morphologically strongly simplified. They develop as Bahiaxenidae) leave their host and are able to move actively. The females of the majority of the 
45 intersegmental membranes with the sclerotized anterior part of their body (Pohl \& Beutel, 46 2008). The primary larvae of Strepsiptera are among the smallest known metazoans with an 47 average size of ca. $230 \mu \mathrm{m}$, comparable to unicellular ciliates of the genus Paramecium (Pohl, 48 2002). This size reduction enables the female to produce a huge number of offspring and the 49 minute primary larvae are able to penetrate relatively small insect hosts such as Delphacidae 50 (Auchenorrhyncha) with an adult size of 1.5-6 mm (Pohl \& Beutel, 2008). The body of the 51 primary larvae is elongated oval to nearly drop shaped. The head is semicircular with well52 developed stemmata with cornea lenses. Antennae are missing and the labrum is not present as a 53 separate element. Sternal plates inserted between the coxae with spinulae and fringes of 54 microtrichia on the posterior border of the abdominal sternites produce capillary forces enabling 55 the larvae to stick to and crawl along wet surfaces (Pohl \& Beutel, 2008). A unique apomorphic 56 in the primary larvae of the Stylopidae (Pohl \& Beutel, 2005).

The relatively sparse Cretaceous fossil record of adult strepsipteran males suggests that 61 they were already a specialized group of insects in the late Mesozoic. It is very likely that the 62 highly modified antennae with flabellate appendages and numerous specialised dome-shaped 63 chemoreceptors were used for finding females over a relatively large distance as in extant species 64 of the group. Likewise, the uptake of food was apparently very limited at least, as suggested by 65 the strongly simplified mouthparts. Strepsipteran females from the Mesozoic have not yet been 66 discovered yet. As with most cases of parasitism documented in the fossil record (e.g. Nagler \& 67 Haug, 2015), Mesozoic Strepsiptera provide only indirect evidence of this specialization. Based 68 on the small size of adult males (ca. 1.5-3 mm), it was assumed, that the species were already 69 endoparasites of other insects (Pohl \& Beutel, 2008). However, conclusive evidence by direct detection of definite strepsipteran larvae was lacking, and therefore direct evidence for an 71 endoparasitic life style of the immature stages of Mesozoic strepsipterans. Previously, 72 endoparasitism was only documented by fossil representatives of Stylopidia from Eocene 73 deposits, the strepsipteran subgroup with permanently endoparasitic females (Kinzelbach \& 74 Pohl, 1994; Henderickx et al., 2013). 
Confirmed fossil records of strepsipteran primary larvae are from the Eocene and Miocene,

76

77

78

79

80

81

82

83

84

85

86

87

88

89

90

91

92

93

94

95

96

97

98

99

100

101

102

103

104

105

respectively. The oldest fossil from Eocene brown coal (Geisel Valley, Germany) was initially described as a first instar of a scale insect (Coccoidea) (Haupt, 1950). It was later assigned to the extant strepsipteran genus Stichotrema (Myrmecolacidae) (Kinzelbach \& Lutz, 1985). Finally, it was placed as Stylopidia incertae sedis based on a re-examination and a cladistic analysis of characters of primary larvae of all extant families of Strepsiptera (Pohl, 2009). Strepsipteran primary larvae associated with its parent female and its host (Auchenorrhyncha: Delphacidae) are reported from Dominican amber (Poinar, 2004), which is currently attributed to the Miocene: 15-20 mya (Iturralde-Vinent \& MacPhee, 1996; Ituralde-Vinent, 2001). Other very small "triungulin" larvae assigned to Strepsiptera were described from the Late Cretaceous (Campanian) amber of Manitoba, Canada (Grimaldi, Kathirithamby \& Schawaroch, 2005), and a "planidium" from the Upper Cretaceous (Santonian) amber of the Taimyr Peninsula, Siberia (Kathirithamby et al., 2017). The interpretation of the immatures treated in the earlier study was discussed critically, pointing out an entire series of features in conflict with an assignment to Strepsiptera (Beutel et al., 2016). The "planidium" from the Upper Cretaceous amber (Kathirithamby et al., 2017) is most likely a parasitic beetle larva based on the following features: small size (ca. $0.53 \mathrm{~mm}$ ), conical head, absence of distinctly developed stemmata, coarse ctenidia, large pretarsal adhesive pad, absence of abdominal segment XI and terminal bristles (Batelka et al., accepted) (see below).

Kathirithamby et al. (2017) used the term "planidium" for primary larvae of Strepsiptera. However, this is only appropriate for legless larvae of parasitic Diptera or Hymenoptera (Askew, 1971; Stehr, 1991). Triungulinid was introduced by Pierce (1909) for first instars of Strepsiptera based on their similarity with primary larvae of Meloidae or Ripiphoridae (Coleoptera), which were addressed as triungulins. However, as the structural affinities are only superficial and obviously non-homologous, and the first instars differ in important features (e.g. nine abdominal segments in Meloidae and Ripiphoridae versus 11 in primary larvae of Strepsiptera), we prefer the neutral term primary larva for first instars of Strepsiptera. Claws forming a trident with spatulate setae occur in phoretic primary larvae of some genera of Meloidae (Bologna, Turco \& Pinto, 2010), but are completely lacking in strepsipteran larvae.

In the present study we describe a minute larva from a piece of Burmese amber, with a habitus and a set of observable features unambiguously confirming a placement in Strepsiptera. 
106 The ordinal assignment among Strepsiptera is discussed. Based on the described features the 107 position of other putative strepsipteran larvae (Grimaldi, Kathirithamby \& Schawaroch, 2005; 108 Kathirithamby et al., 2017) is critically re-evaluated. The new fossil larva clearly confirms that 109 Mesozoic Strepsiptera were already endoparasites of other insects. The origin of endoparasitism 110 is extended back by ca. 50 million years to a minimum of ca. $100 \mathrm{Ma}$.

111

\section{Material \& Methods}

113 Material

114 The piece of Burmese amber with the strepsipteran larva came from deposits in the Hukawng 115 Valley of Myanmar. The age is estimated as ca. $99 \mathrm{Ma}$ (earliest Cenomanian (Shi et al., 2012)).

116 The amber with the strepsipteran first instar (accession number BU-002386) is integrated 117 into the collection of the Institute of Zoology, Chinese Academy of Sciences (Box 92, Beichen 118 West Road, Chaoyang District, Beijing, 100101, P. R. China) and will be deposited in the Three 119 Gorges Entomological Museum, Chongqing, China after 2027. It is from a mining locality at 120 Noije Bum (near Tanai Village, 26²1'33.41'’N, 96²3'11.88'’E) (Cruickshank \& Ko, 2003; 121 Grimaldi, Engel \& Nascimbene, 2009). The size of the piece of amber is $26 \times 22 \times 10 \mathrm{~mm}$. 122 Syninclusions are listed in the following: Acari (9 specimens), orthopteran nymph (1), Psocodea 123 (1), Sternorrhyncha (1), apocritan Hymenoptera (2), Berothidae (Neuroptera) (1), Elateridae (1), 124 primary longipedes larvae of Ripiphoridae (46), Polyphaga with unclear affinity (2), 125 "nematoceran" species of Diptera with unclear affinity (2), brachyceran species of Diptera with 126 unclear affinity (2).

127 As important syninclusions are embedded very close to the strepsipteran larva, it was not 128 possible to isolate the larva and trim the amber piece into a thin plate and mount it on a glass 129 microscope slide. This precludes examining the first instar with oil-immersion lenses and phase 130 or differential interference contrast at a magnification of $1000 \mathrm{x}$. Therefore, some structures of 131 the minute larva could not be evaluated.

132

\section{Specimen imaging}

134 The piece of amber was temporarily mounted on coverslips using glycerine. The specimen was 135 observed under two different microscopes: An Axio Zoom.V16 with a PlanNeoFluar Z 1.0x 136 (Carl Zeiss Microscopy $\mathrm{GmbH}$ ) was used for the overview images and the images were saved as 
137 CZI files. For observations and for measurements ZEN 2.3 lite (blue edition) (Carl Zeiss 138 Microscopy $\mathrm{GmbH}$ ) was used. For higher magnifications, an Olympus IX81 inverted 139 fluorescence microscope with UIS2 objectives, equipped with an ORCA-AG monochromatic 12140 bit CCD camera (Hammatsu) was used. The mirror images were superimposed with Cell^ $\mathrm{R}$ 141 software (Olympus Soft Imaging Solutions). Sets of photographs were analyzed with Fiji 142 (Schindelin et al., 2012).

143 Single images were exported with ZEN 2.3 lite or Fiji respectively. Some images were 144 combined with Zerene Stacker (Zerene Systems LLC, Richland, USA). The photographs were 145 processed using Adobe Photoshop ${ }^{\circledR}$ CS6 (Adobe System Incorporated, San Jose, USA) and 146 arranged as plates. Adobe Illustrator ${ }^{\circledR}$ CS6 (Adobe Systems Incorporated, San Jose, USA) was 147 used for the lettering of the plates. Image stacks of the Olympus IX81 microscope were used for 148 the drawings and description.

149

\section{Comparative taxonomy and terminology}

151 Data on the morphology of Strepsiptera larvae are taken from (Pohl, 2000; 2002) and the 152 morphological nomenclature used in these studies is applied. Additionally, primary larvae of 153 Eoxenos laboulbenei Peyerimhoff, 1919 and Mengenilla chobauti Hofeneder, 1910 (both 154 Mengenillidae) were examined (research collection of H.P. at Phyletisches Museum). For 155 comparison primary larvae of E. laboulbenei embedded in Canada balsam on glass microscope 156 slides were examined with the same microscope (Olympus IX81) as the fossil.

157

158 Results

159 Preservation

160 Strongly depressed dorsoventrally, dorsal and ventral side thus difficult to distinguish, especially 161 in abdominal region. Part of left side of head and thorax covered by debris (Fig. 1A).

162

\section{Morphology}

164 First instar extremely small, total length excluding terminal bristles $197 \mu \mathrm{m}$. Head semicircular, 165 with recognizable stemmata but lacking antennae. Sides of body subparallel, slightly convex. 166 Dorsum smooth, without recognizable surface structures and largely devoid of setae. Terminal 
167 abdominal segment XI with two pairs of strongly developed bristles. Specimen preserved in 168 ventral position

169 Exposed part of head capsule semicircular in ventral view, with evenly rounded anterior 170 margin and greatest width at hind margin. Visible part distinctly shorter than maximum width.

171 Six large individual stemmata with cornea lenses recognizable posterolaterally on left side in 172 strongly pigmented area, only three visible on right side (st in Figs. 1A, B, 2A). Labrum not 173 present as separate element. Evenly rounded anterior margin of head capsule apparently forming 174 sharp edge, lacking median emargination (Figs. 1A, B, 2A, B). Antennae not recognizable as 175 prominent structures, largely reduced. Antennal field likely represented by small circular 176 structure adjacent to anteriormost stemma, visible through translucent cuticle (af in Figs. 1B, 177 2A). Mandibles not visible. Ventral side of head medially covered by strongly modified maxillae 178 and labium. Maxillae medially fused, forming slightly curved, transverse plate-like structure 179 (Figs. 1B, 2B). Maxillary palps recognizable as circular spots on posterior maxillary margin (mp 180 in Figs. 1B, 2B). Details of labium not visible. Paired anterior tentorial arms visible in 181 posterolateral cephalic region (te in Figs. 1B, 2B). Ecdysial sutures not visible. One seta 182 recognizable on dorsal surface (fs in Fig. 1 B). Cuticle without recognizable surface 183 modifications.

184 Pro-, meso- and metathorax subequal in length on ventral side. Only inflicted lateral margin 185 of nota visible (Fig. 1). Thoracic segments continuously widening from anterior to posterior. 186 Prothorax with one seta on lateral pronotal margin, visible on right side. Conspicuous sternal 187 plate inserted between coxae (prsp in Figs. 1B, 2A). Anterior part of sternal plate broad, 188 posterior part with triangular apex. Spinulae on posterior margin not visible. Meso- and 189 metathorax very similar to prothorax, but sternal plate only visible on the former. Legs only 190 partly visible, short, composed of large, transverse coxa, trochanterofemur, tibia, and one191 segmented pad-like tarsus (Fig. 1B). Tarsus without claws. Hind leg with long seta on mesal 192 margin of coxa.

193 Abdomen composed of eleven segments. Segment II broadest, following segments slightly 194 tapering posteriorly (Fig. 1). Only lateral margins of tergites visible, with two lateral setae on 195 most of them (Figs. 1B, 3A, B). Sternites I-IX half as long as thoracic segments. One short seta 196 visible on right side of sternite III, inserted close to hind margin. Sternites IV-VI with two setae 197 inserted laterally close to hind margin (Fig. 1B). Very fine parallel longitudinal lines on margins 
198 of sternites I-VIII may represent spinulae, or alternatively tergal furrows visible through cuticle 199 (Fig. 3A). Tergites IX and X fused, about as long as segments VI-VIII combined, forming large 200 plate-like structure covering terminal segment XI (Fig. 4A). Hind margin of segment XI 201 truncated, with pair of very strongly developed bristles inserted close to midline, and second 202 similar but shorter pair more laterally (Figs. 1B, 3B, 4B).

203

\section{Diagnosis}

205 Differs from primary larvae of Eoxenos laboulbenei by the presence of six stemmata and from 206 primary larvae of Mengenilla chobauti (both Mengenillidae) and all other known primary larvae of Strepsiptera by the strongly developed second pair of bristles on hind margin of segment XI.

\section{Discussion}

210 The larva can be easily and unambiguously assigned to Strepsiptera, based on several diagnostic

211 features and also apomorphic character states shared with other first instars of the order. Like 212 extant strepsipteran primary larvae (Pohl, 2000) the fossil has an elongated oval to drop shaped 213 body, with a semicircular head with large stemmata with cornea lenses, but lacking a separate 214 labrum and also antennae as visible prominent structures. One pair of long and strongly 215 developed bristles inserted on the terminal abdominal segment XI is present (Figs. 1, 5A, B). 216 Within Strepsiptera, the larva shows close structural affinities with first instars of Eoxenos 217 laboulbenei, especially due to the identical equipment with bristles on the last abdominal 218 segments (Figs. 4, 5). A placement close to the root of Strepsiptera s.l. or s.str. is likely. 219 However, as only the male adults of extant Bahiaxenos and the extinct $\uparrow$ Mengea, $\uparrow$ Protoxenos 220 (both Eocene Baltic amber), †Cretostylops, $\dagger$ Kinzelbachilla, and $\dagger$ Phthanoxenos, (Cretaceous 221 Burmese amber) are known (Grimaldi, Kathirithamby \& Schawaroch, 2005; Pohl, Beutel \& 222 Kinzelbach, 2005; Bravo et al., 2009; Pohl \& Beutel, 2016; Engel et al., 2016), a precise 223 phylogenetic assessment is not possible. It is conceivable that the larva belongs to one of the 224 three strepsipteran species known from the same fossil site, but a verification is not possible with 225 the information at hand.

226 A major point demonstrated here is that this Cretaceous primary larva of Strepsiptera differ 227 only in minimal details from extant immatures of basal genera of the order (Mengenillidae). This 
228 documents a high evolutionary stability over ca. 100 million years and clearly suggests that these 229 extremely miniaturized larvae were already parasitic and produced in high numbers.

230 Large stemmata for identification of a host and the abdominal jumping apparatus are

231 features clearly linked with parasitism, and the extremely small size suggests a very high number 232 of offspring like in extant groups (Pohl \& Beutel, 2008).

233 The finding of a Cretaceous primary larva nearly identical with those of the extant genus 234 Eoxenos sheds new light on recently described "planidia" assigned to Strepsiptera 235 (Kathirithamby et al., 2017). Considering the clearly demonstrated evolutionary stability of the 236 tiny first instars, it appears highly unlikely that at the same time aberrant and unusually large 237 strepsipteran primary larvae occurred. The "planidia" described by Kathirithamby et al. (2017) 238 differ in many features from strepsipteran larvae, such as for instance much larger size (ca. 0.5 $239 \mathrm{~mm}$ ), anteriorly conical head, absence of large stemmata ("presumably two stemmata"), presence 240 of a membranous cervix, presence of ctenidia, posteriorly widening meso- and metanota, absence 241 of sternal plates, strongly widened femora, lack of setae and spines on the abdominal sternites, 242 only ten abdominal segments, lacking terminal bristles (on segment XI in Strepsiptera), and 243 consequently the lack of a jumping apparatus. It is much more likely that these were simply 244 miniaturized parasitic beetle larvae (Beutel et al., 2016), although their family placement is still 245 open to debate (Batelka et al., accepted). All observed features are compatible with a placement 246 in polyphagan beetles. The presence of coarse ctenidia and a pad-like pretarsal adhesive device 247 are apomorphic features linking it clearly with beetle larvae very likely belonging to the 248 cucujiform family Ripiphoridae (Beutel et al., 2016; Batelka et al., accepted).

249 Considering the large number of primary larvae produced by strepsipteran females of 250 Mengenillidae (ca. 2,500 by a $5 \mathrm{~mm}$ large female of E. laboulbenei (Silvestri, 1941)), it is 251 surprising at first glance that not more strepsipteran primary larvae have been found in amber. 252 The larva we describe here was only found by chance, like the primary larva from Eocene brown 253 coal (Voigt, 1938). Due to their extremely small size, the larvae are only visible with high 254 magnification $(100 \mathrm{x})$ and can be overlooked very easily. In contrast to primary longipedes 255 larvae of Ripiphoridae (Batelka et al., accepted), extant primary larvae of Strepsiptera show no 256 aggregation behaviour (personal observations of H. Pohl, 2018). After emerging from the female, 257 the larvae quickly disperse in search of a suitable host. Considering their very small size, their 258 radius of activity is probably limited to a few meters. 


\section{Conclusions}

261 Detailed investigations of Burmese amber revealed the first definitive strepsipteran primary larva 262 from the Cretaceous. Diagnostic features are the size of less than $200 \mu \mathrm{m}$, an elongated oval 263 body, a semicircular head, and stemmata with cornea lenses in a strongly pigmented area. 264 Apomorphic character states shared with other primary larvae of Strepsiptera are the lack of a 265 separate labrum and prominent antennae, the medially fused maxillae, sternal plates, and the 266 presence of a pair of long and strongly developed bristles inserted on the terminal abdominal 267 segment XI. An evolutionary stability over ca. 100 million years is revealed as the Cretaceous 268 primary larva of Strepsiptera differs only in minimal details from extant Mengenillidae, the 269 sistergroup of the vast majority of the Strepsiptera (ca. $97 \%$ of the species). The recently 270 described "planidium" assigned to Strepsiptera by Kathirithamby et al. (2017) differs in many 271 characters from fossil and extant primary larvae of Strepsiptera and is very likely a parasitic 272 beetle larva.

273

274 Acknowledgments

275 We are grateful to Mr. Weiwei Zhang for providing pieces of amber used in the context of 276 another publication, and to Assoc. Prof. Ming Bai for arranging this loan. The authors thank 277 Ondřej Šebesta (Charles University) for his help with examination setup on the Olympus IX81 278 and Birgit Perner (Leibniz-Institut für Alternsforschung - Fritz-Lippmann-Institut, Jena) for 279 providing us access to the Axio Zoom.V16. We also thank Benjamin Naumann (Friedrich280 Schiller-Universität Jena) for his help with the Axio Zoom.V16. Finally, we would like to thank 281 Kenneth De Baets, Kateřina Votýpková and one anonymous reviewer for their helpful 282 suggestions, which improved the manuscript.

283

\section{References}

285 Askew RR 1971. Parasitic insects. London: Heinemann Educational Books Ltd.

286 Batelka J, Prokop J, Pohl H, Bai M, Zhang W, Beutel RG accepted. Highly specialized 287 Cretaceous beetle parasitoids (Ripiphoridae) identified with optimized visualization of 288 microstructures. Systematic Entomology. 
289 Beutel RG, Zhang WW, Pohl H, Wappler T, Bai M 2016. A miniaturized beetle larva in

290

291

292

293

294

295

296

297

298

299

300

301

302

303

304

305

306

307

308

309

310

311

312

313

314

315

316

317

318

319

Cretaceous Burmese amber: reinterpretation of a fossil "strepsipteran triungulin." Insect Systematics \& Evolution 47:83-91.

Bologna MA, Turco F, Pinto JD 2010. 11.19. Meloidae Gyllenhal, 1810. In: Leschen RAB, Beutel RG, Lawrence JF eds. Handbook of Zoology. New York, 681-693.

Bravo F, Pohl H, Silva-Neto A, Beutel R 2009. Bahiaxenidae, a "living fossil" and a new family of Strepsiptera (Hexapoda) discovered in Brazil. Cladistics 25:614-623.

Cruickshank RD, Ko K 2003. Geology of an amber locality in the Hukawng Valley, Northern Myanmar. Journal of Asian Earth Sciences 21:441-455.

Engel MS, Huang D, Breitkreuz LCV, Azar D, Cai C, Alvarado M 2016. A new twisted-wing parasitoid from mid-Cretaceous amber of Myanmar (Strepsiptera). Cretaceous Research $58: 160-167$.

Grimaldi DA, Engel MS, Nascimbene PC 2009. Fossiliferous Cretaceous amber from Myanmar (Burma): Its rediscovery, biotic diversity, and paleontological significance. American Museum Novitates 3361:1-71.

Grimaldi D, Kathirithamby J, Schawaroch V 2005. Strepsiptera and triungula in Cretaceous amber. Insect Systematics \& Evolution 36:1-20.

Haupt H 1950. Die Käfer (Coleoptera) aus der eozänen Braunkohle des Geiseltals. Geologica. Schriftenreihe der geologischen Institute der Universitäten Berlin, Greifswald, Halle, Rostock 6:VII-168.

Henderickx H, Bosselaers J, Pauwels E, van Hoorebeke L, Boone M 2013. X-ray micro-CT reconstruction reveals eight antennomeres in a new fossil taxon that constitutes a sister clade to Dundoxenos and Triozocera (Strepsiptera: Corioxenidae). Palaeontologia Electronica $16: 1-16$.

Iturralde-Vinent, MA 2001. Geology of the amber-bearing deposits of the greater Antilles. Carribean Journal of Science 37:141-166.

Iturralde-Vinent MA, MacPhee RDE 1996. Age and paleogeographical origin of Dominican amber. Science 273:1850-1852.

Kathirithamby J, Perkovsky EE, Falin ZH, Engel MS 2017. A putative twisted-wing parasitoid planidium (Insecta: Strepsiptera) in Taimyr Upper Cretaceous amber. Cretaceous Research 69:106-112.

Peer] reviewing PDF | (2018:07:30075:2:0:NEW 6 Oct 2018) 
320 Kinzelbach R, Lutz H 1985. Stylopid larva from the Eocene - a spotlight on the phylogeny of the

321

322

323

324

325

326

327

328

329

330

331

332

333

334

335

336

337

338

339

340

341

342

343

344

345

346

347

348

stylopids (Strepsiptera). Annals of the Entomological Society of America 78:600-602.

Kinzelbach R, Pohl H 1994. The fossil Strepsiptera (Insecta: Strepsiptera). Annals of the Entomological Society of America 87:59-70.

Kjer KM, Simon C, Yavorskaya M, Beutel RG 2016. Progress, pitfalls and parallel universes: a history of insect phylogenetics. Journal of the Royal Society Interface 13:20160363.

McKenna DD, Wild AL, Kanda K, Bellamy CL, Beutel RG, Caterino MS, Farnum CW, Hawks DC, Ivie MA, Jameson ML, Leschen RAB, Marvaldi AE, McHugh JV, Newton AF, Robertson JA, Thayer MK, Whiting MF, Lawrence JF, Ślipiński A, Maddison DR, Farrell BD 2015. The beetle tree of life reveals that Coleoptera survived end-Permian mass extinction to diversify during the Cretaceous terrestrial revolution. Systematic Entomology $40: 835-880$.

McMahon DP, Hayward A, Kathirithamby J 2011. The first molecular phylogeny of Strepsiptera (Insecta) reveals an early burst of molecular evolution correlated with the transition to endoparasitism. PLOS ONE 6:e21206.

Misof B, Liu S, Meusemann K, Peters RS, Donath A, Mayer C, Frandsen PB, Ware J, Flouri T, Beutel RG, Niehuis O, Petersen M, Izquierdo-Carrasco F, Wappler T, Rust J, Aberer AJ, Aspöck U, Aspöck H, Bartel D, Blanke A, Berger S, Böhm A, Buckley TR, Calcott B, Chen J, Friedrich F, Fukui M, Fujita M, Greve C, Grobe P, Gu S, Huang Y, Jermiin LS, Kawahara AY, Krogmann L, Kubiak M, Lanfear R, Letsch H, Li Y, Li Z, Li J, Lu H, Machida R, Mashimo Y, Kapli P, McKenna DD, Meng G, Nakagaki Y, Navarrete-Heredia JL, Ott M, Ou Y, Pass G, Podsiadlowski L, Pohl H, Reumont von BM, Schütte K, Sekiya K, Shimizu S, Ślipiński A, Stamatakis A, Song W, Su X, Szucsich NU, Tan M, Tan X, Tang M, Tang J, Timelthaler G, Tomizuka S, Trautwein M, Tong X, Uchifune T, Walzl MG, Wiegmann BM, Wilbrandt J, Wipfler B, Wong TKF, Wu Q, Wu G, Xie Y, Yang S, Yang Q, Yeates DK, Yoshizawa K, Zhang Q, Zhang R, Zhang W, Zhang Y, Zhao J, Zhou C, Zhou L, Ziesmann T, Zou S, Li Y, Xu X, Zhang Y, Yang H, Wang J, Wang J, Kjer KM, Zhou X 2014. Phylogenomics resolves the timing and pattern of insect evolution. Science 346:763-767.

Nagler C, Haug JT 2015. From fossil parasitoids to vectors: insects as parasites and hosts. Advances in Parasitology 90:137-200. 
350 Niehuis O, Hartig G, Grath S, Pohl H, Lehmann J, Tafer H, Donath A, Krauss V, Eisenhardt C,

351

352

353

354

355

356

357

358

359

360

361

362

363

364

365

366

367

368

369

370

371

372

373

374

375

376

377

378

379

380

Hertel J, Petersen M, Mayer C, Meusemann K, Peters RS, Stadler PF, Beutel RG, Bornberg-

Bauer E, McKenna DD, Misof B 2012. Genomic and morphological evidence converge to resolve the enigma of Strepsiptera. Current Biology 22:1309-1313.

Peters RS, Meusemann K, Petersen M, Mayer C, Wilbrandt J, Ziesmann T, Donath A, Kjer KM, Aspöck U, Aspöck H, Aberer A, Stamatakis A, Friedrich F, Hünefeld F, Niehuis O, Beutel RG, Misof B 2014. The evolutionary history of holometabolous insects inferred from transcriptome-based phylogeny and comprehensive morphological data. BMC Evolutionary Biology 14:52.

Pierce W 1909. A monographic revision of the twisted winged insects comprising the order Strepsiptera Kirby. Bulletin of the United States National Museum 66:1-232.

Pohl H 2000. Die Primärlarven der Fächerflügler - evolutive Trends (Insecta, Strepsiptera). Kaupia, Darmstädter Beiträge zur Naturgeschichte 10:1-144.

Pohl H 2002. Phylogeny of the Strepsiptera based on morphological data of the first instar larvae. Zoologica Scripta 31:123-134.

Pohl H 2009. The oldest fossil strepsipteran larva (Insecta: Strepsiptera) from the Geisel Valley, Germany (Eocene). Insect Systematics \& Evolution 40:333-347.

Pohl H, Beutel RG 2005. The phylogeny of Strepsiptera (Hexapoda). Cladistics 21:328-374.

Pohl H, Beutel RG 2008. The evolution of Strepsiptera (Hexapoda). Zoology 111:318-338.

Pohl H, Beutel RG 2013. The Strepsiptera-Odyssey: the history of the systematic placement of an enigmatic parasitic insect order. Entomologia 1:e4.

Pohl H, Beutel RG 2016. $\dagger$ Kinzelbachilla ellenbergeri-a new ancestral species, genus and family of Strepsiptera (Insecta). Systematic Entomology 41:287-297.

Pohl H, Beutel RG, Kinzelbach R 2005. Protoxenidae fam. nov (Insecta, Strepsiptera) from Baltic amber - a "missing link" in strepsipteran phylogeny. Zoologica Scripta 34:57-69.

Poinar G 2004. Evidence of parasitism by Strepsiptera in Dominican amber. Biocontrol 49:239244.

Schindelin J, Arganda-Carreras I, Frise E, Kaynig V, Longair M, Pietzsch T, Preibisch S, Rueden C, Saalfeld S, Schmid B, Tinevez J-Y, White DJ, Hartenstein V, Eliceiri K, Tomancak P, Cardona A 2012. Fiji: an open-source platform for biological-image analysis. Nature Methods 9:676-682. 
381 Shi G, Grimaldi DA, Harlow GE, Wang J, Wang J, Yang M, Lei W, Li Q, Li X 2012. Age 382 constraint on Burmese amber based on $\mathrm{U}-\mathrm{Pb}$ dating of zircons. Cretaceous Research 383 $37: 155-163$.

384 Silvestri F 1941. Studi sugli "Strepsiptera" (lnsecta). I. Ridescrizione e ciclo dell'Eoxenos 385 Laboulbenei Peyerimhoff. Bolletino del Laboratorio di Zoologia generale e agraria della 386 Facoltà Agraria in Portici 31:311-341.

387 Stehr F 1991. Immature insects. Michigan: Kendall/Hunt.

388 Toussaint EFA, Seidel M, Arriaga-Varela E, Hájek J, Král D, Sekerka L, Short AEZ, Fikáček M 389 2017. The peril of dating beetles. Systematic Entomology 42:1-10.

390 Voigt E 1938. Weichteile an fossilen Insekten aus der eozänen Braunkohle des Geiseltales bei 391 Halle (Saale). Nova Acta Leopoldina, Neue Folge 6:1-38.

392

393 
394 Figure 1 Strepsiptera primary larva in Burmese amber, ventral view. A. Photomicrograph with 395 an Axio Zoom.V16 with a PlanNeoFluar Z 1.0x. B. Drawing based on photomicrographs with an 396 Olympus IX81 inverted fluorescence microscope with UIS2 objective. Abbreviations: af = 397 antennal field, $\mathrm{cb}=$ caudal seta, $\mathrm{cx}=\mathrm{coxa}, \mathrm{fe}=$ femur, $\mathrm{fs}=$ frontal seta, $\mathrm{lcb}=$ lateral caudal seta, $398 \mathrm{mp}=$ maxillary palp, $\mathrm{mssp}=$ mesosternal plate, $\mathrm{mt}=$ metanotum, $\mathrm{mx}=$ maxilla, prsp $=$ prosternal 399 plate, $\operatorname{sbsIX} / \mathrm{X}=$ segmental border between abdominal sternites IX/X, sbtVIII/IX = segmental 400 border between abdominal tergites VIII/IX, sI-sIX = abdominal sternites I-XI, st $=$ stemmata, ta $401=$ tarsus, te $=$ tentorium, $\mathrm{ti}=$ tibia, $\mathrm{X}=$ abdominal segment $\mathrm{X}, \mathrm{XI}=$ abdominal segment $\mathrm{XI}$.

402

403 Figure 2 A, B. Strepsiptera primary larva in Burmese amber, head, pro-, and mesothorax, ventral 404 view. C, D. Eoxenos laboulbenei, head, pro-, and mesothorax, ventral view. Photomicrographs 405 with an Olympus IX81 inverted fluorescence microscope with UIS2 objective. Abbreviations: af 406 $=$ antennal field, $\cos =$ coxal seta, $\mathrm{lb}=$ labium, $\mathrm{mp}=$ maxillary palp, $\mathrm{mssp}=$ mesosternal plate, 407 $\mathrm{mx}=$ maxilla, $\mathrm{prsp}=$ prosternal plate, $\mathrm{st}=$ stemmata, te $=$ tentorium, $\mathrm{ti}=$ tibia.

Figure 3 A, B. Strepsiptera primary larva in Burmese amber. A. Meso-, metathorax, and anterior

abdominal segments, ventral view. B. Terminal abdominal segments. C, D. Eoxenos laboulbenei.

411 C. Abdominal segments III-IX, ventral view. D. Terminal abdominal segments.

412 Photomicrographs with an Olympus IX81 inverted fluorescence microscope with UIS2 413 objective. Abbreviations: $\mathrm{cb}=$ caudal bristle, $\mathrm{lcb}=$ lateral caudal bristle, $\mathrm{sbsIX} / \mathrm{X}=$ segmental 414 border between sternite IX and $\mathrm{X}, \operatorname{sbs} \mathrm{X} / \mathrm{XI}=$ segmental border between sternite $\mathrm{X}$ and $\mathrm{XI}$, $415 \mathrm{sbtVIII} / \mathrm{IX}=$ segmental border between tergite VIII and $\mathrm{IX}$, ti $=$ tibia, $\mathrm{X}=$ abdominal segment $\mathrm{X}$, $416 \mathrm{XI}=$ abdominal segment XI.

418 Figure 4 Terminal segments of Strepsiptera primary larva in Burmese amber, drawings based on 419 photomicrographs with an Olympus IX81 inverted fluorescence microscope with UIS2 objective.

420 A. Dorsal view. B. Ventral view. Abbreviations: sbsIX/X = segmental border between abdominal 421 sternites IX/X, sbtVIII/IX = segmental border between abdominal tergites VIII/IX, X = 422 abdominal segment $\mathrm{X}, \mathrm{XI}=$ abdominal segment XI. 
424 Figure 5 Primary larva of Eoxenos laboulbenei, drawings based on scanning electron 425 micrographs (modified from Pohl, 2000). A. Ventral view. B. Dorsal view. Abbreviations: af = 426 antennal field, $\mathrm{cb}=$ caudal bristle, $\mathrm{cx}=\mathrm{coxa}, \mathrm{fe}=$ femur, $\mathrm{fs}=$ frontal seta, $\mathrm{lb}=$ labium, $\mathrm{lcb}=$ 427 lateral caudal bristle, $\mathrm{mp}=$ maxillary $\mathrm{palp}, \mathrm{mx}=$ maxilla, $\mathrm{prsp}=$ prosternal plate, $\mathrm{sI}-\mathrm{sXI}=$ 428 abdominal sternite $\mathrm{I}-\mathrm{XI}, \mathrm{st}=$ stemma, $\mathrm{ta}=$ tarsus, $\mathrm{ti}=$ tibia, $\mathrm{tI}-\mathrm{tX}=$ abdominal tergite $\mathrm{I}-\mathrm{X}$. 


\section{Figure 1}

Strepsiptera primary larva in Burmese amber, ventral view.

A. Photomicrograph with an Axio Zoom.V16 with a PlanNeoFluar Z 1.0x. B. Drawing based on photomicrographs with an Olympus IX81 inverted fluorescence microscope with UIS2 objective. Abbreviations: $a f=$ antennal field, $c b=$ caudal seta, $c x=c o x a, f e=$ femur, $f s=$ frontal seta, $\mathrm{Icb}=$ lateral caudal seta, $\mathrm{mp}=$ maxillary palp, $\mathrm{mssp}=$ mesosternal plate, $\mathrm{mt}=$ metanotum, $m x=$ maxilla, $\operatorname{prsp}=$ prosternal plate, $\operatorname{sbs} I X / X=$ segmental border between abdominal sternites IX/X, sbtVIII/IX = segmental border between abdominal tergites VIII/IX, sI-sIX = abdominal sternites I-XI, st $=$ stemmata, ta $=$ tarsus, te $=$ tentorium, $\mathrm{ti}=$ tibia, $\mathrm{X}=$ abdominal segment $\mathrm{X}, \mathrm{XI}=$ abdominal segment $\mathrm{XI}$. 

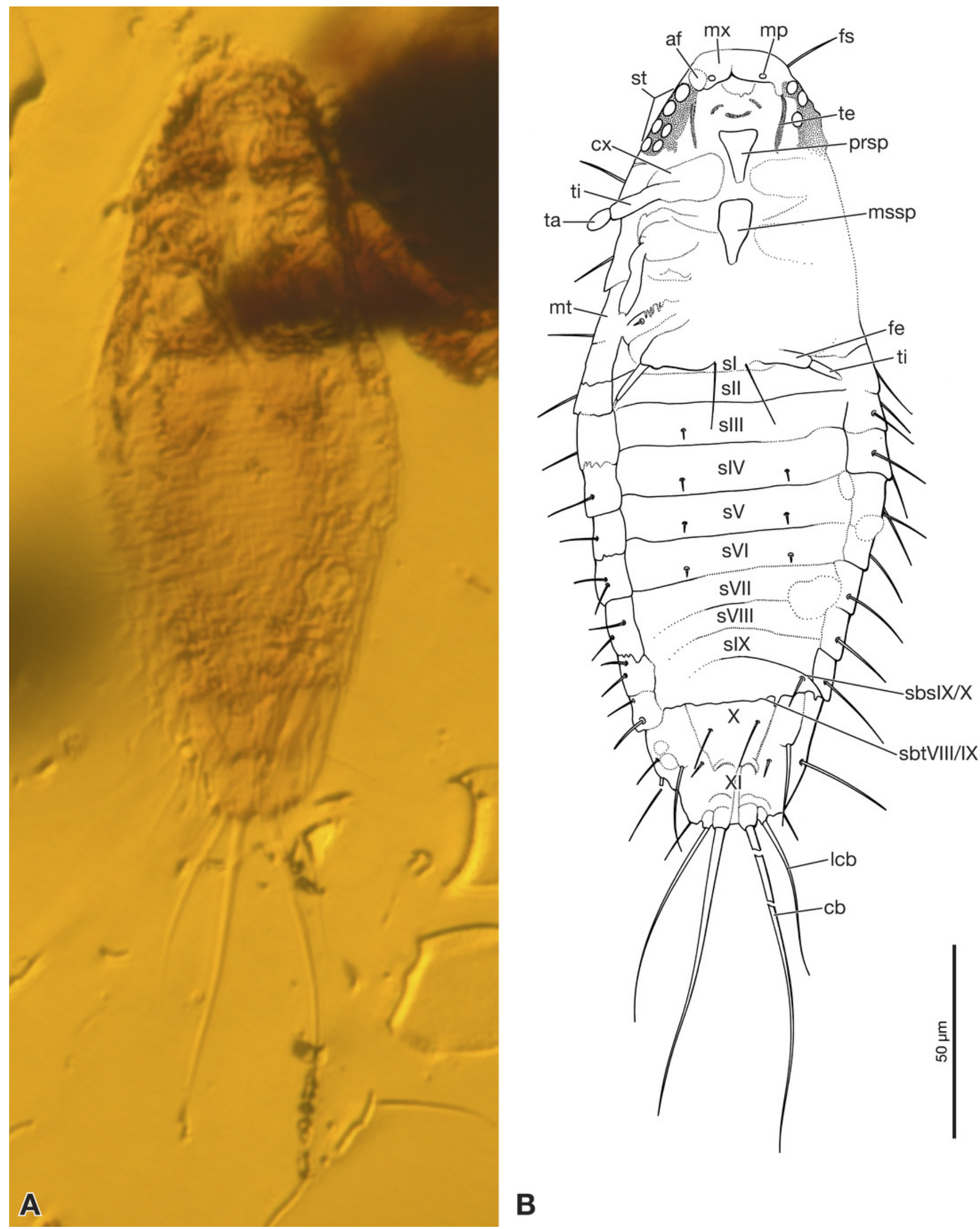

B 


\section{Figure 2}

Strepsiptera primary larva in Burmese amber in comparison with an extant primary larva.

A, B. Strepsiptera primary larva in Burmese amber, head, pro-, and mesothorax, ventral view. C, D. Eoxenos laboulbenei, head, pro-, and mesothorax, ventral view. Photomicrographs with an Olympus IX81 inverted fluorescence microscope with UIS2 objective. Abbreviations: af = antennal field, $\cos =$ coxal seta, $\mathrm{lb}=$ labium, $\mathrm{mp}=$ maxillary palp, $\mathrm{mssp}=$ mesosternal plate, $\mathrm{mx}=$ maxilla, $\mathrm{prsp}=$ prosternal plate, $\mathrm{st}=$ stemmata, te $=$ tentorium, $\mathrm{ti}=$ tibia. 

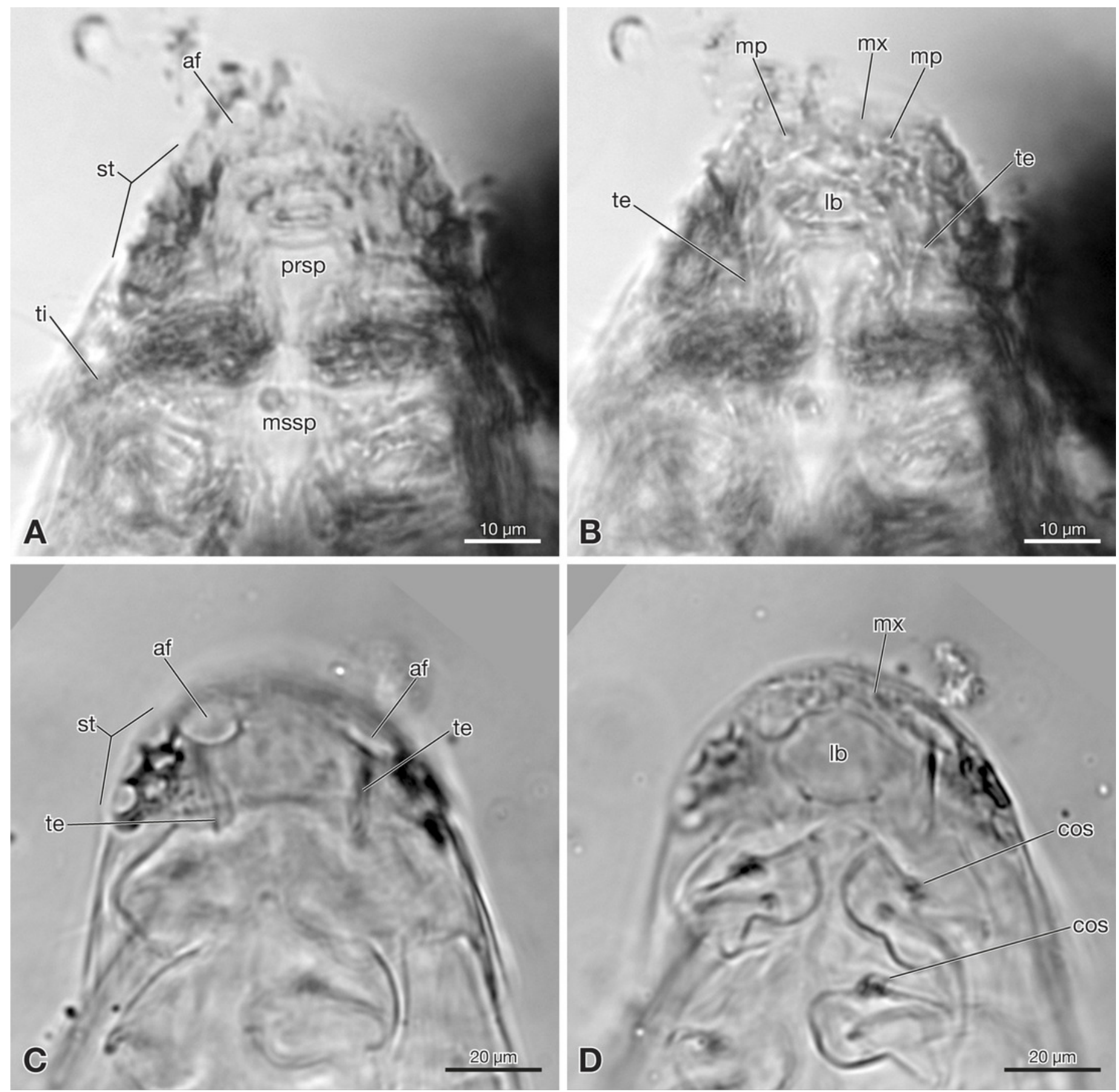


\section{Figure 3}

Strepsiptera primary larva in Burmese amber in comparison with an extant primary larva.

A, B. Strepsiptera primary larva in Burmese amber. A. Meso-, metathorax, and anterior abdominal segments, ventral view. B. Terminal abdominal segments. C, D. Eoxenos laboulbenei. C. Abdominal segments III-IX, ventral view. D. Terminal abdominal segments. Photomicrographs with an Olympus IX81 inverted fluorescence microscope with UIS2 objective. Abbreviations: $c b=$ caudal bristle, $I c b=$ lateral caudal bristle, $\operatorname{sbs} \mid X / X=$ segmental border between sternite $I X$ and $X, \operatorname{sbs} X / X I=$ segmental border between sternite $X$ and $X I$, sbtVIII/IX = segmental border between tergite VIII and IX, ti = tibia, $X=$ abdominal segment $\mathrm{X}, \mathrm{XI}=$ abdominal segment $\mathrm{XI}$. 


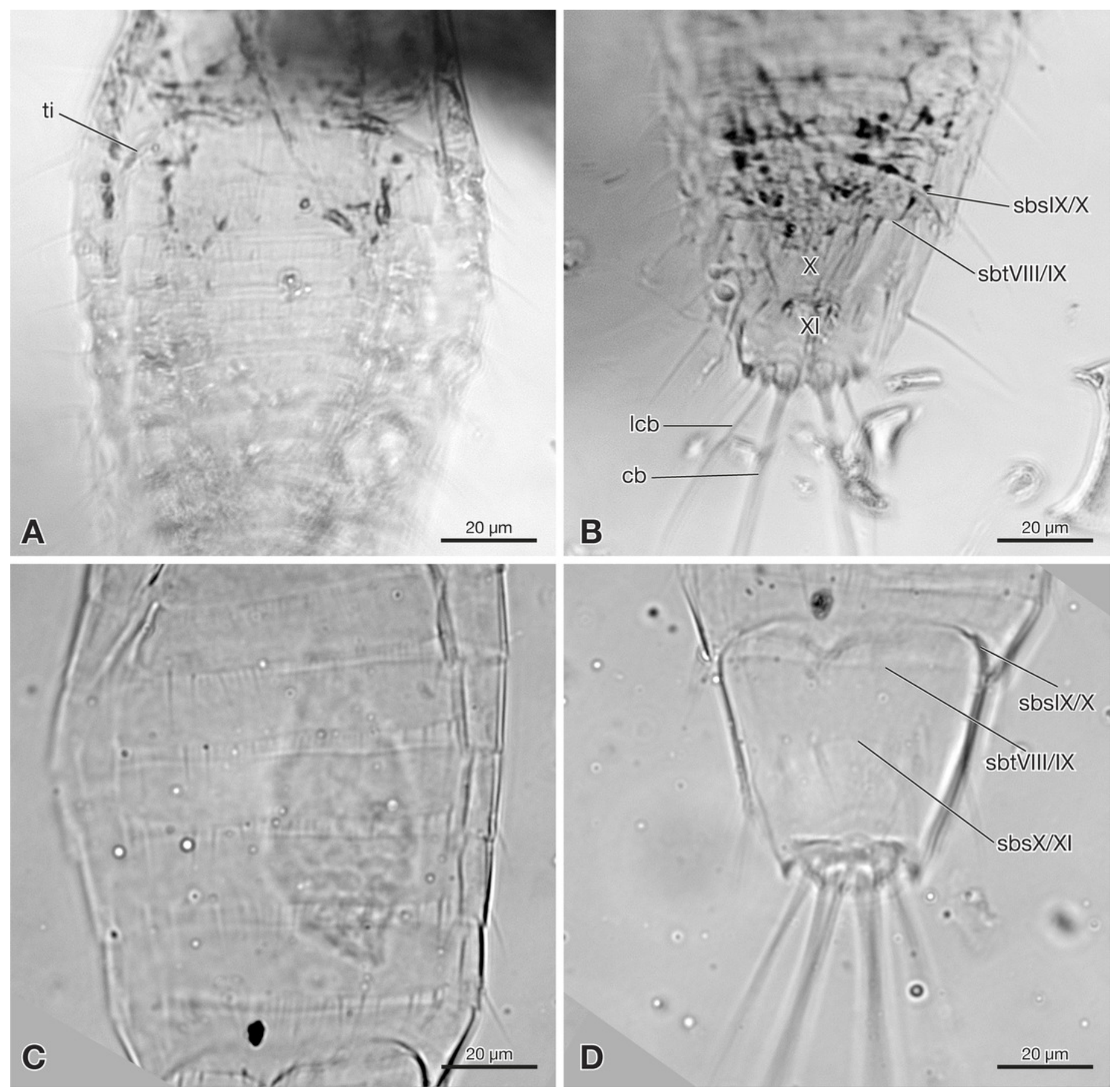


Figure 4

Terminal segments of Strepsiptera primary larva in Burmese amber, drawings based on photomicrographs with an Olympus IX81 inverted fluorescence microscope with UIS2 objective.

A. Dorsal view. B. Ventral view. Abbreviations: sbslX/X = segmental border between abdominal sternites IX/X, sbtVIII/IX = segmental border between abdominal tergites VIII/IX, X $=$ abdominal segment $\mathrm{X}, \mathrm{XI}=$ abdominal segment $\mathrm{XI}$.
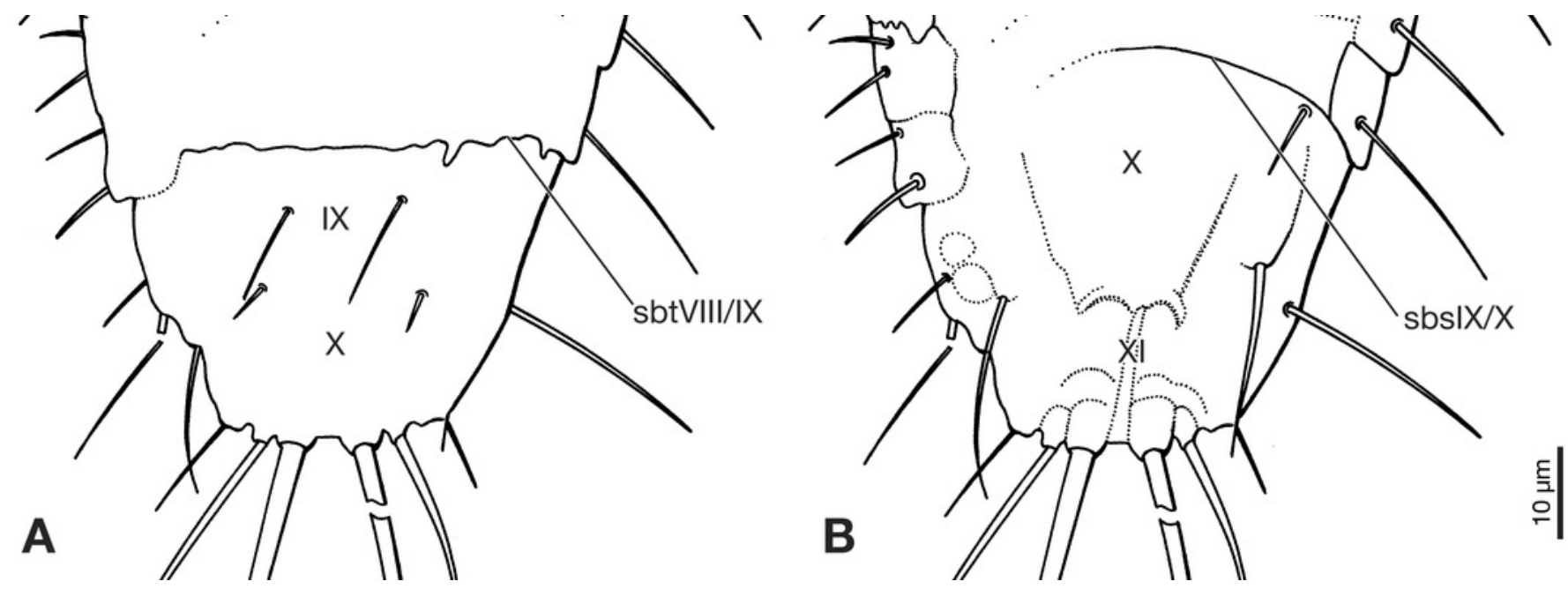


\section{Figure 5}

Primary larva of Eoxenos laboulbenei, drawings based on scanning electron micrographs (modified from Pohl, 2000).

A. Ventral view. B. Dorsal view. Abbreviations: $a f=$ antennal field, $c b=$ caudal bristle, $c x=$ coxa, $f e=$ femur, $f s=$ frontal seta, $\mathrm{lb}=$ labium, $\mathrm{Icb}=$ lateral caudal bristle, $\mathrm{mp}=$ maxillary palp, $\mathrm{mx}=$ maxilla, $\mathrm{prsp}=$ prosternal plate, $\mathrm{sI}-\mathrm{sXI}=$ abdominal sternite I-XI, st $=$ stemma, ta $=$ tarsus, $\mathrm{ti}=$ tibia, $\mathrm{tl}-\mathrm{tX}=$ abdominal tergite $\mathrm{I}-\mathrm{X}$. 

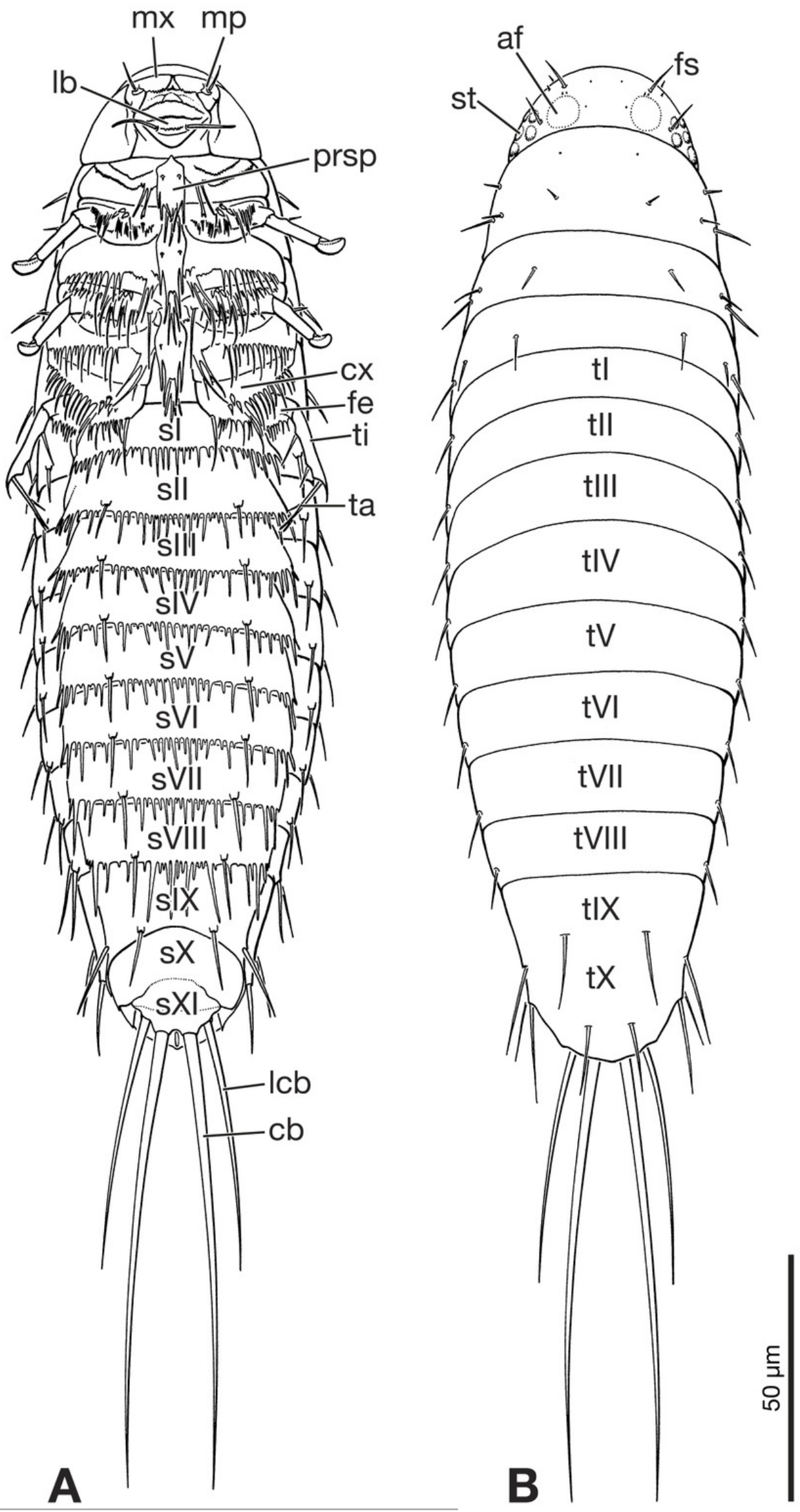